\title{
EFFECT OF INFORMATION PROCESSING AND DEPTH PERCEPTION UPON THROWING ACCURACY OF BASKETBALL PLAYERS
}

Singh Virendra Kumar ${ }^{1}$, Agashe Chandrakant D. ${ }^{2}$

${ }^{1}$ Shri Shankaracharya Mahavidyalaya, India

${ }^{2}$ Pt. Ravishankar Shukla University, India

\begin{abstract}
Annotation. Purpose: The purpose of the present study is to analyze throwing accuracy of basketball players in relation to their reasoning ability and depth perception. Materials and Methods : For present study, 200 intercollegiate basketball players (Ave. age $=21.34 \pm 1.87$ years) were selected as sample. Johnson Basketball Throw for Accuracy (Passing Test) was the instrument which was used to assess shooting skills of selected subjects whereas reasoning ability of the selected subjects was assessed by MGTI prepared by Mehrotra (1984). To conduct the study, a $2 \times 2$ factorial design was used. Superior and inferior reasoning and perceptual abilities were ascertained by statistical method Q1 and Q3. 2x2 ANOVA results showed that the main effect of reasoning ability was not found to be statistically significant upon throwing accuracy of basketball players although it is close to .05 level of significance. Results : The main effect of depth perception upon throwing accuracy of basketball players turned out to be statistically significant. The two factor interaction effect of reasoning ability and depth perception upon throwing accuracy of basketball players was found to be statistically insignificant. Conclusion: It was concluded that reasoning ability and to some extent depth perception, are the two major variables which generate variance upon throwing accuracy of basketball players.
\end{abstract}

Keywords: information processing, depth perception, throwing accuracy, basketball.

\section{Introduction}

Player's activity during a match requires specific skills such as visual information acquisition and speed at which they process information. Researchers in the past have also showed the importance of visual skills in sports performance $[1,2,3]$. Similarly speed of information processing or reasoning ability has also been emerged as potential variable as far as performance is concerned $[4,5,6,7,8]$

In a sport such as basketball, good perception of depth may enables a player to accurately judge the distance between the player and other players, the role of speed of information processing or reasoning ability may also be important because of the nature of the sport which is fast paced and requires quick thinking and judgmental ability to perform fundamental ability such as throwing or passing.

Perception refers to the process of taking in, organizing, and interpreting sensory information. Perception is multimodal, with multiple sensory inputs contributing to motor responses [9]. Depth perception refers to the ability to see and understand the 3-D spatial relationship and relative distance between objects and oneself. Its primary value is to make hand-eye coordination efficient and provide for safe movement through space. Binocular depth perception is one of the most demanding visual tasks that we carry out. The horizontal separation of the eyes in the head means that each eye obtains an image of the world from a slightly different viewpoint. The differences between these images, called binocular disparities, present significant challenges that the brain's visual system must overcome in order to make use of them. Binocular vision must be highly accurate: the CNS needs to be able to register a difference between the two eyes that is smaller than the width of a single cone photo receptor. To extract these fine differences, individual features in the left eye's image must be matched with the correct partner features in the right eye.

Reasoning refers to the process of drawing conclusions or inferences from information. Reasoning always requires going beyond the information that is given [10]. In logic, an inference is called deductive if the truth of the initial information (or premises) guarantees the truth of the conclusion. The inference is called inductive if the truth of the premises makes the conclusion probable but not certain. Distinctions between deductive and inductive reasoning can be important in understanding logic; but in practice, these distinctions may exist more in the mind of the researcher developing a task than in the performance of examinees on that task. Many researchers have found that performance on deductive and inductive tests is strongly related.

When people reason, they must, in Bruner's (1957) helpful phrase, go "beyond the information given". They do this in one or both of the following ways: They attempt to infer (either automatically or deliberately) concepts, patterns, or rules that best (i.e., most uniquely) characterize the relationships or patterns they perceive among all the elements (e.g., words, symbols, figures, sounds, movements) in a stimulus set. Better reasoning is characterized by the use of concepts or rules that simultaneously satisfy the opposing needs for abstraction (or generalization) and specificity. Such concepts or rules tend to be at least moderately abstract yet precisely tuned. Put differently, a poor inference is often vague and captures only a subset of the relationships among the elements in the set. They attempt to deduce the consequences or implications of a rule, set of premises, or statements using warrants that are rendered plausible by logic or by information that is either given in the problem or assumed to be true within the community of discourse. They often seem to do this by creating and manipulating mental models of the situation. Such models tend to represent explicitly only what is assumed to be true about the situation. Better reasoning involves providing warrants that are more plausible or consistent with the rules of logic or the conditions embodied in a comprehensive mental

(c) Singh Virendra Kumar, Agashe Chandrakant D., 2015

http://dx.doi.org/10.15561/20755279.2015.0206 
model. More advanced deductive reasoning involves providing either multiple (possibly divergent) warrants for a single claim or an increasingly sophisticated chain of logically connected and separately warranted assertions.

John-Laird's mental models theory of deductive reasoning posits that the individual first transforms the premises of an argument into another representation that is consistent with the premises. Importantly, multiple mental models that are consistent with the premises must often be constructed and then compared in order to reach a valid conclusion. Each mental model represents a possible state of affairs that must be evaluated.[11] Bara, Bucciarelli, and Johnson-Laird (1995) identified the following factors that affect syllogistic inference in the mental models approach: (a) assembling a propositional representation of premises; (b) constructing models that integrate information from premises; (c) formulating a conclusion which integrates relationships not expressed in the premises; (d) searching for alternative models to refute conclusions; and (e) recognizing similarities between models. All these processes require working memory resources.[12]

Human reasoning occurs at different levels of awareness. Most cognitive scientists distinguish between tacit and intentional (or explicit) reasoning processes. Tacit processes that facilitate reasoning occur without conscious intervention and outside awareness; they typically do not require attention. Such thinking is sometimes described as associative, because it depends on the network of ideas and associations in memory. Tacit processes are used when we make a decision in a quick or intuitive way, often because it feels right rather than because we have a clearly articulated set of reasons. We are aware of the outcome of these tacit processes, but not of the processes themselves. Tacit processes are particularly important in focusing attention and in building an initial mental model of a problem. Effective problem solvers typically attend to different features of the problem than do less effective problem solvers. Effective problem solvers know what to seek and know what to ignore. In part, this is due to greater experience; in part, to better use of past experiences. Other researchers describe this automatic attention as the extent to which the person is attuned to certain aspects of a situation and not others.

Although researchers studied various facets of basketball [13, 14, 15, 16, 17] but while scanning through the research literature, it was observed that throwing accuracy of basketball players has not been studied so far, hence the researcher aimed to study the joint effect of depth perception and reasoning ability upon throwing accuracy of basketball players.

\section{Materials and Methods}

\section{Ethics}

The research was carried out with prior permission from Basketball Association of Chhattisgarh and the participants written consent to take part in this study.

Sample

For present study, 200 intercollegiate basketball players (Ave. age $=21.34 \pm 1.87$ years) were selected as sample. The selection of subjects was done from Inter-collegiate tournaments held in the State of Chhattisgarh India. The selection of sample was based on convenience sampling technique.

\section{Tools and Procedure}

To assess throwing accuracy of selected basketball players, Johnson Basketball Throw for Accuracy (Passing Test) was used. This test is highly reliable and valid. The direction of scoring for this test is "higher the score better is the ability"[18].

Mehrotra's (1984) Mixed Type Group Test of Intelligence (MGTI) was used to assess reasoning ability of selected subjects,. It has two parts i.e. verbal and non verbal intelligence test. Both the parts have 50 statements. The test-retest reliability of the verbal test is 0.89 , for non verbal test it is 0.82 while full test reliability coefficient is 0.86 . The validity verbal test is .86 and for non verbal test it is 0.72 while the overall validity of the test is 0.87 when it was correlated with teacher's ratings. Only non-verbal intelligence part was used in the present investigation [19].

Depth perception of the selected subjects was recorded by a specially designed depth perception apparatus. In this test the direction is scoring is "higher the deviation, lower the binocular depth perception" [20].

Johnson Basketball Throw for Accuracy (Passing Test) was administered to selected basketball players under the supervision of investigator. Similarly experiments on depth perception apparatus was performed by the subjects under personal supervision of the investigator. The reasoning ability part of MGTI test was administered to each selected basketball player in a peaceful corner. The response pertaining to MGTI was scored off as per author's manual. Scores on Johnson basketball throw for accuracy test and depth perception was also recorded for each selected subject.

To divide cases into superior and inferior reasoning ability, $\mathrm{Q}_{1}$ and $\mathrm{Q}_{3}$ statistical technique was used. Subjects whose reasoning ability scores lies below Q1 was assigned to inferior reasoning ability category, and subjects whose scores lies above Q3 was assigned to superior reasoning ability category. Regarding bifurcating the scores of depth perception into superior and inferior categories, again $\mathrm{Q}_{1}$ and $\mathrm{Q}_{3}$ statistical technique was used. Subjects whose depth perception scores lies below Q1 was assigned to superior depth perception category, subjects whose scores lies above Q3 was assigned to inferior depth perception category.

To find out the joint action effect of depth perception (superior-Inferior) and reasoning ability (SuperiorInferior) on throwing accuracy of basketball players, 2x2 ANOVA technique was adopted. The results are presented in table 1 and 1(a) respectively. 


\section{Results}

Table 1

Reasoning Ability (A) x Depth Perception (B) on Throwing Accuracy of Basketball Players (N=73)

\begin{tabular}{|l|c|c|c|}
\hline \multirow{2}{*}{} & \multicolumn{2}{|c|}{ Depth Perception (B) } & M \\
\cline { 2 - 4 } & $\mathrm{b}_{1}$ & $\mathrm{~b}_{2}$ \\
Inferior & $\mathrm{M}=11.40$ \\
\hline $\mathrm{a}_{1}$ & Superior & $\mathrm{N}=05$ & 14.46 \\
Superior & $\mathrm{M}=17.53$ & $\mathrm{M}=9.16$ & 11.88 \\
\hline $\mathrm{a}_{2}$ & $\mathrm{~N}=39$ & $\mathrm{~N}=24$ & \\
Inferior & $\mathrm{M}=14.60$ & $\mathrm{~N}=05$ & 10.28 \\
\hline $\mathrm{M}$ & 16.06 & \\
\hline
\end{tabular}

Table 1 (a)

ANOVA Summary

\begin{tabular}{|c|c|c|c|c|}
\hline $\begin{array}{c}\text { Source of } \\
\text { Variation }\end{array}$ & SS & df & MS & F \\
\hline $\mathrm{A}$ & 57.237 & 1 & 57.237 & $3.49(\mathrm{NS})$ \\
\hline $\mathrm{B}$ & 286.549 & 1 & 286.549 & $17.50^{* *}$ \\
\hline $\mathrm{AB}$ & 1.064 & 1 & 1.064 & $0.06(\mathrm{NS})$ \\
\hline $\begin{array}{c}\text { Within treatment } \\
\text { (Error) }\end{array}$ & 1129.426 & 69 & 16.368 & \\
\hline
\end{tabular}

From the analysis of table 1 and 1 (a) following inferences were drawn:

The main effect of reasoning ability upon throwing accuracy of basketball players was not found to be statistically significant but it was close to statistical significance. The reported $F=3.49(p<.06)$, although not statistically significant gives a clear trend that subjects with superior reasoning ability $(M=14.46)$ have significantly better throwing accuracy as compared to subjects with inferior reasoning ability $(\mathrm{M}=11.88)$.

The F of 17.50, an indicator of the main effect of depth perception upon throwing accuracy of basketball players turned out to be statistically significant. It thereby reveals that subjects with subjects with superior depth perception $(M=16.06)$ have significantly better throwing accuracy as compared to subjects with inferior depth perception $(\mathrm{M}=10.28)$ at .01 level of statistical significance.

The two factor interaction effect of depth perception and reasoning ability upon throwing accuracy of basketball players was not found to be statistically significant $(F=0.06, p>.05)$.

\section{Discussion:}

In the present study, the main effect of reasoning ability upon throwing accuracy of basketball players was not found to be statistically significant $\mathrm{F}=3.49, \mathrm{p}<.06$ ) but it is very close to statistical significance at .05 level. This fact is also confirmed by the graphical representation of mean throwing accuracy test scores shown in Fig. (i) denotes a significant slope in the curve which is not parallel to the $X$ axis and thus proves the partial significant main effect of reasoning ability upon throwing accuracy of basketball players. The similar results were also obtained in the past [21]. Hence, speed of information processing or in other words reasoning ability is a potential enough variable to influence basic fundamental skill in basketball i.e. field goal shooting skills. 


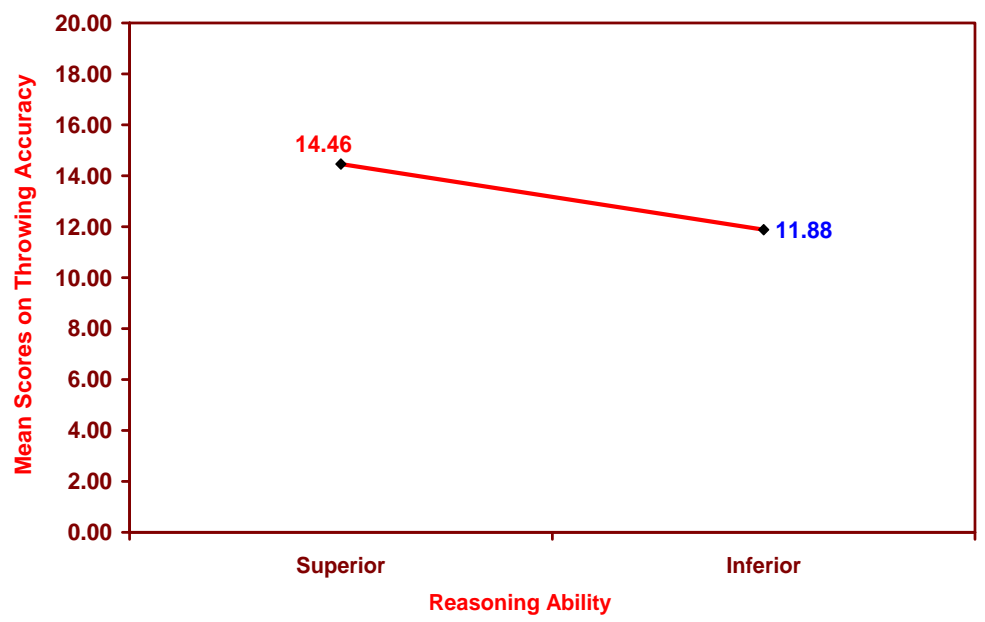

Figure (i). Line Diagram Showing Main Effect of Reasoning Ability on Throwing Accuracy of Basketball Players

In the present study, the main effect of depth perception upon throwing accuracy of basketball players was found to be statistically significant. This fact is also confirmed by the graphical representation of mean throwing accuracy scores shown in Fig. (ii) which denotes a significant slope in the curve which is not parallel to the $\mathrm{X}$ axis and thus proves the significant main effect of depth perception upon throwing accuracy of basketball players. Accurately throwing a ball in basketball requires a players to judge relative distance between objects and his own position in three dimensional space. Hence, a player who judgment of this distance is superior invariably throws the ball accurately. Hence the results of the present study are in expected direction.

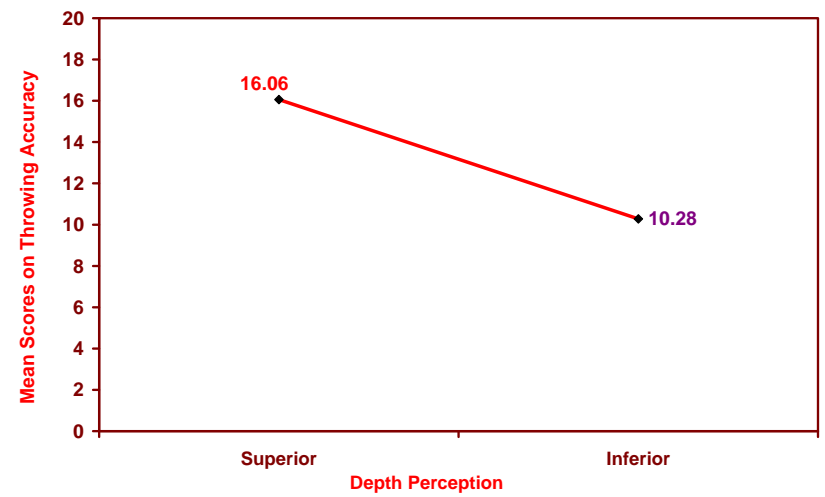

Figure (ii). Line Diagram Showing Main Effect of Depth Perception on Throwing Accuracy of Basketball Players

The two factor interaction effect of depth perception and reasoning ability was not found to be statistically significant. This fact is verified by parallel lines, which shows that each factor displayed the independence from other factor and not generating variance upon mental health jointly or in interaction with each other (Fig. iii).

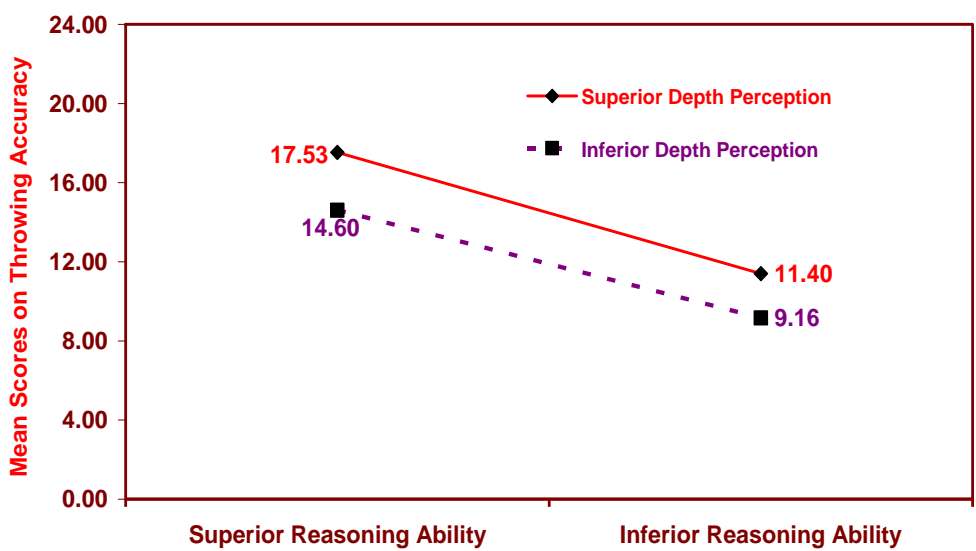

Figure (iii). Line Diagram Showing Interaction Effect of Depth Perception and Reasoning Ability on Throwing Accuracy of Basketball Players 


\section{Conclusions}

Hence on the basis of results it was concluded that depth perception fully and reasoning ability partially, have a significant impact upon throwing accuracy of basketball players but same cannot be said about joint action effect of these two variables upon throwing accuracy of basketball players.

\section{References}

1. Adolphe R.M., Vickers, J.N. and La Plante G. The effects of training visual attention on gaze behavior and accuracy. International Journal of Sports Vision. 1997, no.4, pp. 28-33.

2. Savelsbergh G.J.P., Williams M.A., Van der Kamp J., Ward P. Visual search, anticipation and expertise in soccer goalkeepers. Journal of Sports Sciences, 2002,no.20, pp. 279-287.

3. Eaves D.L, Anderton and Taylor M. Is visual perception the key to success in young soccer players. Perception, 36, ECVP, 2007, 240 p.

4. Vernon P. A., \& Mori M. Intelligence, reaction times, and peripheral nerve conduction velocity. Intelligence, 1992, no.16, pp. 273-288.

5. Kioumourtzoglou E., Derri V., Tzetzis G. \& Theodorakis Y. Cognitive, perceptual and motor abilities in skilled basketball performance. Perceptual and motor skills, 1998, no.86, pp. 771-786.

6. Planinsec J., Pisot R. Motor coordination and intelligence level in adolescents. Adolescence. 2006, vol.41, no.164, pp. 667-676.

7. Karalejic M. and Jakovljevic S. Cognitive abilities of young basketball players and their actual success. Physical Culture, 2008, vol.62, no.1-2, pp. 117-123.

8. Kamkary K., Akbari P., Shokrzadeh S. Effects of Personality Profiles and Profiles of IQ on Elite Athletes Volleyball's Performance. European Journal of Experimental Biology, 2012, vol.2, no. 6, pp. 2352-2359.

9. Bertenthal B. I. Origins and Early Development of Perception, Action and Representation. Annual Review of Psychology, 1996, vol.47, pp. 431-459.

10. Bruner J. S. Going beyond the information given. In Contemporary approaches to cognition: A symposium held at the University of Colorado. Cambridge, MA: Harvard University Press, 1957, pp. 41-69.

11. Johnson-Laird P. N. Mental models and reasoning. In J. P. Leighton, \& R. J. Sternberg (Eds.), The nature of reasoning New York, NY: Cambridge University Press, 2004, pp. 169-204.

12. Bara B. G., Bucciarelli M., Johnson-Laird P. N. Development of syllogistic reasoning. American Journal of Psychology, 1995, no.108, pp. 157-193.

13. Pates J., Maynard I., Westbury T. An investigation into the effects of hypnosis on basketball performance. Journal of Applied Sport Psychology, 2001, no.13, pp. 84-102.

14. Poczwardowski A., Fisher M. The impact of mental preparation on free throw shooting and self-efficacy with collegiate basketball players: A psychological skills training approach. Poster presentation, European Federation of Sport Psychology Congress, Copenhagen, Denmark. 2001, pp. 100-106.

15. Pates T.; Frewan M., Beer J. Association of eye colour and sex with basketball free throws by elementary school children. Perceptual and motor skills. 1991, no.73, pp. 1181-1182.

16. Balcinuas M. Long term effects of different training modalities on power, speed, skill and anaerobic capacity in young male basketball players. Journal of Sports Science and Medicine, 2006, no.5, pp. 163-170.

17. Quintana M.S., Roman I.R., Molinuevo. Perceptual visual skills in young highly skilled basketball players. Perceptual and motor skills, 2007, no.104, pp. 547-561.

18. Kansal D.K. Test and Measurement in Sports and Physical Education. 1996, pp. 294-296.

19. Mehrotra P.N. Manual for mixed type of group test of intelligence (Verbal and non-verbal), Agra National Psychological Corporation, Agra. 1984, 240 p.

20. Shahbazi, M., Taher, A. V., \& Hadadi, N. Effects of Viewer-Induced Arousal on Depth Perception in Male and Female Athletes. Procedia - Social and Behavioral Sciences, 2011, no.15, pp. 3103-3107. http://doi.org/10.1016/j.sbspro.2011.04.253

21. Cashmore E. Making Sense of Sports, London, Routledge, 2005, 212 p. 
Information about the authors:

Virendra Kumar Singh: http://orcid.org/0000-0003-1225-254X sukritivksingh@hotmail.com; Shri Shankaracharya Mahavidyalaya; 97/2 Junwani, Bhilai, Distt. Durg, Chhattisgarh, 490020, India.

Agashe Chandrakant D.: http://orcid.org/0000-0003-0226-714X cagash@yahoo.com; Pt. Ravishankar Shukla University; Amanaka G.E.Road, Raipur, Chhattisgarh, 492010, India.

Cite this article as: Singh Virendra Kumar, Agashe Chandrakant D. Effect of information processing and depth perception upon throwing accuracy of basketball players. Physical education of students, 2015 , no.2, pp. 37-42. http://dx.doi.org/10.15561/20755279.2015.0206

The electronic version of this article is the complete one and can be found online at: http://www.sportpedu.org.ua/html/arhive-e.html

This is an Open Access article distributed under the terms of the Creative Commons Attribution License, which permits unrestricted use, distribution, and reproduction in any medium, provided the original work is properly cited (http:// creativecommons.org/licenses/by/3.0/deed.en).

Received: 12.02 .2015

Accepted: 12.03.2015; Published: 30.04.2015 